\title{
W-band waveguide bandpass filter with E-plane cut
}

\author{
Furtula, Vedran; Salewski, Mirko
}

Published in:

Review of Scientific Instruments

Publication date:

2014

Document Version

Publisher's PDF, also known as Version of record

Link back to DTU Orbit

Citation (APA):

Furtula, V., \& Salewski, M. (2014). W-band waveguide bandpass filter with E-plane cut. Review of Scientific Instruments, 85(7), 074703.

\section{General rights}

Copyright and moral rights for the publications made accessible in the public portal are retained by the authors and/or other copyright owners and it is a condition of accessing publications that users recognise and abide by the legal requirements associated with these rights.

- Users may download and print one copy of any publication from the public portal for the purpose of private study or research.

- You may not further distribute the material or use it for any profit-making activity or commercial gain

- You may freely distribute the URL identifying the publication in the public portal

If you believe that this document breaches copyright please contact us providing details, and we will remove access to the work immediately and investigate your claim. 


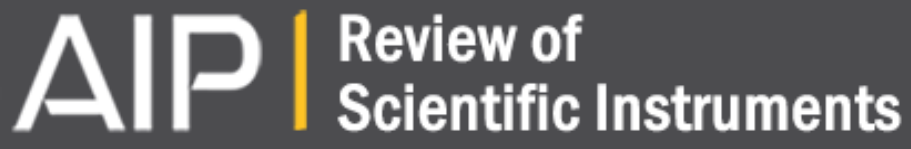

\section{W-band waveguide bandpass filter with E-plane cut}

Vedran Furtula and Mirko Salewski

Citation: Review of Scientific Instruments 85, 074703 (2014); doi: 10.1063/1.4889875

View online: http://dx.doi.org/10.1063/1.4889875

View Table of Contents: http://scitation.aip.org/content/aip/journal/rsi/85/7?ver=pdfcov

Published by the AIP Publishing

\section{Articles you may be interested in}

High-power microwave filters and frequency selective surfaces exploiting electromagnetic wave tunneling through -negative layers

J. Appl. Phys. 113, 064909 (2013); 10.1063/1.4790584

A tunable universal terahertz filter using artificial dielectrics based on parallel-plate waveguides Appl. Phys. Lett. 97, 131106 (2010); 10.1063/1.3495994

Design, simulation, and measurement of metamaterial absorber

J. Appl. Phys. 108, 034906 (2010); 10.1063/1.3311964

A filter bank system for scattered spectrum analysis in collective Thomson scattering diagnostic on JT-60

Rev. Sci. Instrum. 71, 4445 (2000); 10.1063/1.1326932

Direct-coupled-cavity bandpass filters using scrounged rectangular-to-circular waveguide transitions

Rev. Sci. Instrum. 71, 4294 (2000); 10.1063/1.1313802
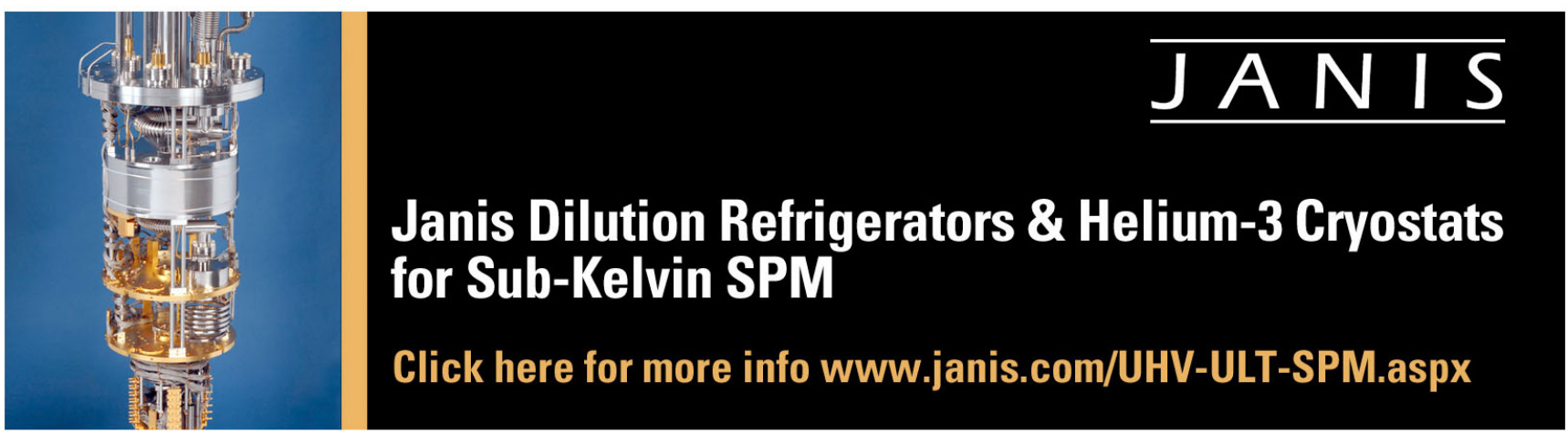


\title{
W-band waveguide bandpass filter with E-plane cut
}

\author{
Vedran Furtula ${ }^{1, a)}$ and Mirko Salewski ${ }^{2, b)}$ \\ ${ }^{1}$ Department of Microtechnology and Nanoscience, Chalmers University of Technology, \\ SE-41296 Gothenburg, Sweden \\ ${ }^{2}$ Department of Physics, Technical University of Denmark, DK-2800 Kgs. Lyngby, Denmark
}

(Received 29 April 2014; accepted 27 June 2014; published online 22 July 2014)

\begin{abstract}
In this paper, we present a design and measurements of a five-section bandpass filter with a passband from 96 to $106 \mathrm{GHz}$. The insertion loss is less than $1.4 \mathrm{~dB}$ in the passband, and the rejection is better than $40 \mathrm{~dB}$ in the range from 115 to $142 \mathrm{GHz}$. We use transmission line coupling theory based on Tchebyscheff's synthesis in order to provide an initial guess for the geometrical parameters of the filter such as cavity lengths and coupling widths. The filter is manufactured from brass in two halves in the E-plane cut topology. The S-parameters of the filter are measured and compared with the simulations. The measured passband insertion loss is approximately $0.4 \mathrm{~dB}$ worse than in the simulation, and the measured passband width is approximately $3.4 \%$ narrower. The measured filter attenuation roll-off corresponds well to the simulation. We also compare our S-parameter measurements of the E-plane filter with corresponding measurements of a very similar H-plane filter. The transmission and reflection characteristics of the E-plane filter are better than those of the H-plane filter. (C) 2014 AIP Publishing LLC. [http://dx.doi.org/10.1063/1.4889875]
\end{abstract}

\section{INTRODUCTION}

Waveguide bandpass filters are widely used in receivers sensitive to radiation coming from fusion plasmas. In fusion plasmas diagnostics the most common mm-wave receivers are total-power radiometers. ${ }^{1}$ For example, the collective Thomson scattering (CTS) diagnostic at ASDEX Upgrade ${ }^{2,3}$ uses a total-power radiometer operating in the frequency range 75$110 \mathrm{GHz}$ (W-band). The CTS diagnostic can detect spectral power densities of a few electronvolts $(\mathrm{eV})$ against the electron cyclotron emission (ECE) background on the order of $100 \mathrm{eV}$. The required CTS probing beam produced by a gyrotron is many orders of magnitude stronger than the signal to be detected. Different frequency ranges within the passband of the bandpass filter are then sensitive to different parts of the ion velocity distribution function in the plasma. ${ }^{4,5}$ At ASDEX Upgrade there are also gyrotrons operating at $140 \mathrm{GHz}$ to heat the plasma by electron cyclotron resonance heating (ECRH). It is therefore important that bandpass filters installed in CTS diagnostics have a high rejection around $140 \mathrm{GHz} .{ }^{6}$ Another type of fusion plasma diagnostic using bandpass filters is ECE spectroscopy where the objective is to determine the evolution of the electron temperature profile as a function of time covering the spectral range from 60 to about $800 \mathrm{GHz} .{ }^{1}$ For example, an ECE diagnostic used to detect neoclassical tearing modes (NTMs) at ASDEX Upgrade monitors radiations in a passband with (bandwidth) of $20 \mathrm{GHz}$ centered at $140 \mathrm{GHz}{ }^{7}$ Future nuclear fusion reactors will also be equipped with mmwave diagnostics since the first mirrors can be designed robust against the harsh radiation environment. ${ }^{8}$ For example, a CTS system for the next-step fusion device ITER is foreseen. ${ }^{9}$ Waveguide filters are also used in $\mathrm{mm}$-wave receivers for at-

a)vfurtula@gmail.com

b) msal@ fysik.dtu.dk mospheric science. For example, a waveguide highpass filter installed in a ground-based $\mathrm{mm}$-wave receiver is used to acquire mesospheric carbon monoxide (CO) data. ${ }^{10}$ The receiver is operated by the British Antarctic Survey (BAS) stationed at Troll station in Antarctica. Another application of waveguide bandpass filters is found in remote sensing where $\mathrm{mm}$-wave spaceborne radars are used to measure air pollution, the distribution of polar ice or vegetation. ${ }^{11}$

Extensive literature exists on waveguide components such as junctions, transitions, filters, and multipliers. ${ }^{12-15}$ Today passive mm-wave components are mostly fabricated using metallic waveguides but recent attempts have been made to design silicon micromachined D-band three-pole and five-pole bandpass filters. ${ }^{16,17} \mathrm{~A}$ comparison between different machining topologies, the E-plane cut and the H-plane cut, has been presented for goldplated submillimeter waveguide filters. ${ }^{18}$ The terms "E-plane cut" and "H-plane cut" refer to the planes parallel to the $\mathbf{E}$-field and the $\mathbf{H}$-field in rectangular waveguides for the fundamental $\mathrm{TE}_{10}$ mode, respectively. Thin-film microstrip-like technology implemented on a benzocyclobutene layer, ${ }^{19,20}$ and reduced size coplanarwaveguide (CPW) resonators, ${ }^{21}$ and annular CPW branchline coupler with open load stubs ${ }^{22}$ have been used in the design of compact W-band bandpass filters. A thin metallic strip inserted in the middle of a waveguide parallel to the E-plane has been used to design a W-band bandpass filter. ${ }^{23}$

In this paper, we present a bandpass filter based on the E-plane cut topology. The filter has five resonator sections (five-pole filter) and is micromachined in brass. The center frequency is $101 \mathrm{GHz}$ and the passband width is $10.37 \mathrm{GHz}$. The upper rejection bandwidth is designed to be large enough to attenuate strong signals coming from the ECRH gyrotrons at $140 \mathrm{GHz}$. Additionally, we compare S-parameter measurements of our E-plane filter with corresponding measurements of a very similar H-plane filter. ${ }^{24}$ 


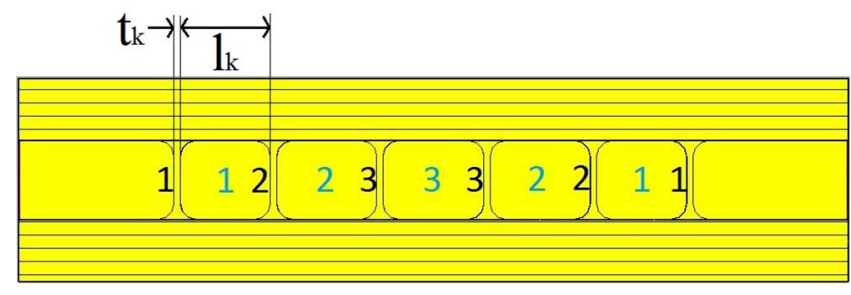

FIG. 1. A five-pole bandpass filter design showing E-plane cut. Blue numbers label cavity sections and black numbers label iris openings. The quantities $t_{k}$ and $l_{k}$ are iris thicknesses and cavity lengths, respectively.

\section{ANALYSIS AND BACKGROUND}

The filter synthesis we use is based on Tchebyscheff's factors with an odd number of sections $n .^{25}$ The symmetry in this situation is illustrated in Figs. 1 and 2: the first section on one side is identical to the first section on the opposite side and the second section on one side is identical to the second section on the opposite side. Hence there are three different sections according to $(n+1) / 2$ and three different iris openings according to $(n+1) / 2$. We use the principle of direct coupling as a technique to cascade resonant sections ${ }^{14}$ where one section corresponds to one pole derived from Tchebyscheff's synthesis. In the direct coupling technique much of the frequency sensitivity between the resonator sections is eliminated (Ref. 14, p. 258), and the filter structure becomes relatively short. The filter is designed as a cascade of sections with approximate lengths of $\lambda_{g} / 2$ connected with very thin couplings (iris openings, see photographs in Figs. 3 and 4) which determine the width of the filter passband. We define the filter passband width in terms of Tchebyscheff's $0.5 \mathrm{~dB}$ ripple level. The quantity $\lambda_{g}$ is the guide wavelength for the fundamental $\mathrm{TE}_{10}$ mode ${ }^{25}$

$$
\lambda_{g}=\frac{\lambda_{0}}{\sqrt{\epsilon_{r} \mu_{r}-\left(\frac{\lambda_{0}}{\lambda_{c}}\right)^{2}}},
$$

where $\lambda_{c}=2 a$ is the cut-off wavelength, $\epsilon_{r} \mu_{r}=1$ for an air-filled waveguide, and $\lambda_{0}$ is the wavelength in vacuum. The waveguide dimensions are set to WR-10 standard corresponding to dimensions $a=2.54 \mathrm{~mm}$ and $b=1.27 \mathrm{~mm}$. In this case, the lower cut-off frequency is around $59 \mathrm{GHz}$ and the first higher order mode is around $118 \mathrm{GHz}$. Detailed design equations used to construct the bandpass filter in this paper are presented in Ref. 24.

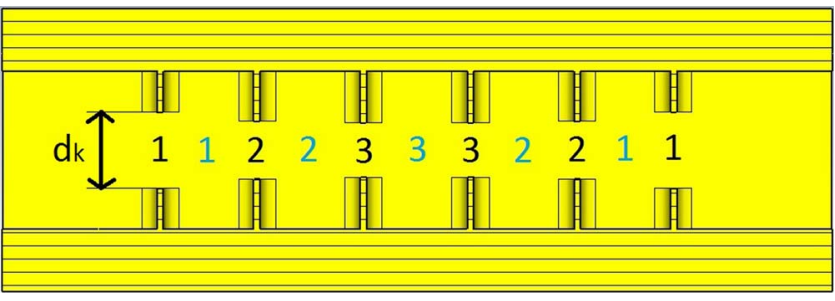

FIG. 2. A five-pole bandpass filter design showing H-plane cut. Blue numbers label cavity sections and black numbers label iris openings. The quantities $d_{k}$ are widths of the iris openings.

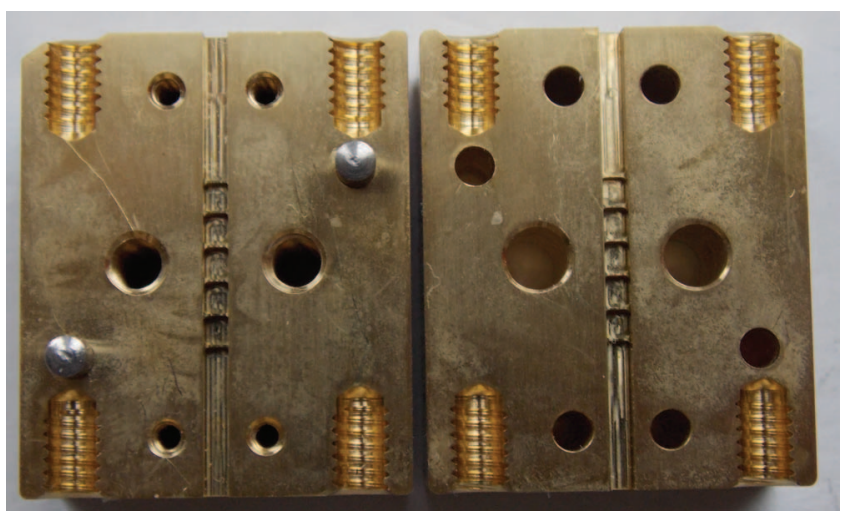

FIG. 3. Photograph showing a topview of the two micromachined symmetrical parts of the bandpass filter using E-plane cut.

\section{E-PLANE BANDPASS FILTER - SIMULATIONS AND MEASUREMENTS}

The design parameters obtained from the design equations based on Tchebyscheff's synthesis are summarized in Table I. These are used to model the waveguide filter in the 3D electromagnetic simulation environment $\mathrm{CST}^{26}$ The Sparameters are calculated using the time domain solver and discrete waveguide ports using more than $2 \times 10^{6}$ meshcells. However, in the intermediate steps for scaling and optimization we have used the much faster frequency domain solver with approximately $5 \times 10^{5}$ meshcells. The waveguide material is brass $(\mathrm{Cu} 70 \%)$ with a conductivity of $1.6 \times 10^{7} \mathrm{~S} / \mathrm{m}$ and a thermal conductivity of $109 \mathrm{~W} /(\mathrm{m} \mathrm{K})$ at room temperature. Simulation results using the initial geometry parameters from Table I do not fit the required passband width of $10 \mathrm{GHz}$ and the center frequency of $101 \mathrm{GHz}$. Therefore, we choose to scale section lengths $l_{k}$ and iris openings $d_{k}$ (see Figs. 1 and 2) in such a way that both the center frequency and the bandwidth match the ideal requirements determined from Tchebyscheff's synthesis. By downscaling or upscaling section lengths $l_{k}$ it is possible to move the center frequency up or down, respectively. By widening or narrowing iris openings $d_{k}$ it is possible to expand or contract the passband,

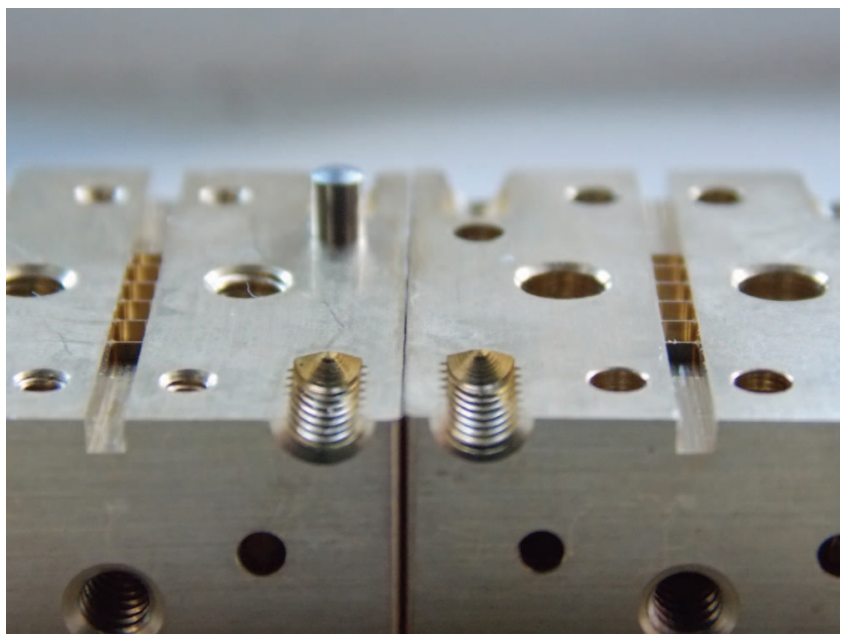

FIG. 4. Photograph of the same filter as in Fig. 3 in diagnonal view showing the cross-cut of WR-10 flanges using E-plane cut topology. 
TABLE I. Section lengths $l_{k}$, iris openings $d_{k}$, and iris thicknesses $t_{k}$ in the initial stage (Tchebyscheff's synthesis and direct coupling) and the final stage (scaled and optimized) for the five-pole bandpass filter.

\begin{tabular}{llcccc}
\hline \hline & Section & $l_{k}(\mathrm{~mm})$ & Iris & $t_{k}(\mathrm{~mm})$ & $d_{k}(\mathrm{~mm})$ \\
\hline \multirow{4}{*}{ Initial } & 1 (and 5) & 1.555 & 1 (and 6) & 0.1 & 1.023 \\
& 2 (and 4) & 1.665 & 2 (and 5) & 0.1 & 0.732 \\
& 3 & 1.681 & 3 (and 4) & 0.1 & 0.670 \\
\hline \multirow{3}{*}{ Final } & 1 (and 5) & 1.458 & 1 (and 6) & 0.1 & 1.224 \\
& 2 (and 4) & 1.618 & 2 (and 5) & 0.1 & 0.920 \\
& 3 & 1.631 & 3 (and 4) & 0.1 & 0.870 \\
\hline \hline
\end{tabular}

respectively. It turns out that the present E-plane filter should be scaled by the factors $\Delta_{l_{k}}=0.98$ and $\Delta_{d_{k}}=0.993$, i.e., the section lengths should be shortened by $2 \%$ and the iris openings should be shortened by only $0.7 \%$ in order to better match the target center frequency and bandwidth. As a last step we choose to optimize section lengths $l_{k}$ and iris openings $d_{k}$ in order to find the optimum geometry for the filter so that we can match the requirements. The filter topology determined by scaling and the optimization is summarized in Table I. The method of optimization used is Trust region framework $^{27}$ where we optimized at most three parameters at a time from the total number of six optimization parameters $\left(l_{k}(3)\right.$ and $\left.d_{k}(3)\right)$. The scaled and optimized values for $l_{k}$ and $d_{k}$ differ less than $6.3 \%$ and $16.4 \%$ from the corresponding initial values determined by the direct coupling theory, respectively.

We fabricated the filter by dividing it into two symmetrical parts, i.e., we use the E-plane cut at the position $a / 2$ where $a$ is the long side of the waveguide. The filter halves are micromachined using a drill with a radius of $0.25 \mathrm{~mm}$ (Ø0.5 mm drill). The two filter halves are connected using two flat head screws $(\varnothing 3 \mathrm{~mm})$ in the middle of the filter and using four socket head screws $(\varnothing 1 \mathrm{~mm})$, two at the input of the filter and two at the output. We measured the performance of the filter using the vector network analyzer (VNA) HP8510C. The VNA is equipped with a WR-10 waveguide interface with the possibility to measure in the range from 75 to $117 \mathrm{GHz}$. The ports are calibrated using standard TRL technique; $\mathrm{T}=$ thru (waveguide ports directly connected), $\mathrm{R}$ $=$ reflect (short at port 1 and port 2$), \mathrm{L}=$ line $(\lambda / 4$ waveguide section between the ports). The intermediate frequency (IF) bandwidth is chosen to be $300 \mathrm{~Hz}$ in the VNA settings, and the number of measurement points is chosen to be 801 . We noted that the S-parameters were very sensitive to the torque applied to the flange screws. Hence, we did not allow an air gap in the transition between two waveguides.

The simulated and measured S-parameters for transmission characteristics $\left(S_{21}\right.$ and $\left.S_{12}\right)$ and matchings $\left(S_{11}\right.$ and $\left.S_{22}\right)$ are presented in Fig. 5, and a zoom in on the passband is shown in Fig. 6. In the simulation, we also assume that $S_{11}$ $=S_{22}$ since we have three symmetry planes in the filter geometry. The shape of the measured $S_{21}$ and $S_{12}$ curves fit remarkably well with the simulations, but the measurements are about $0.4 \mathrm{~dB}$ worse than predicted in the simulations (see Fig. 6). The measured passband width is $10.37 \mathrm{GHz}$, while the simulated one is $10.68 \mathrm{GHz}$, i.e., a discrepancy of about

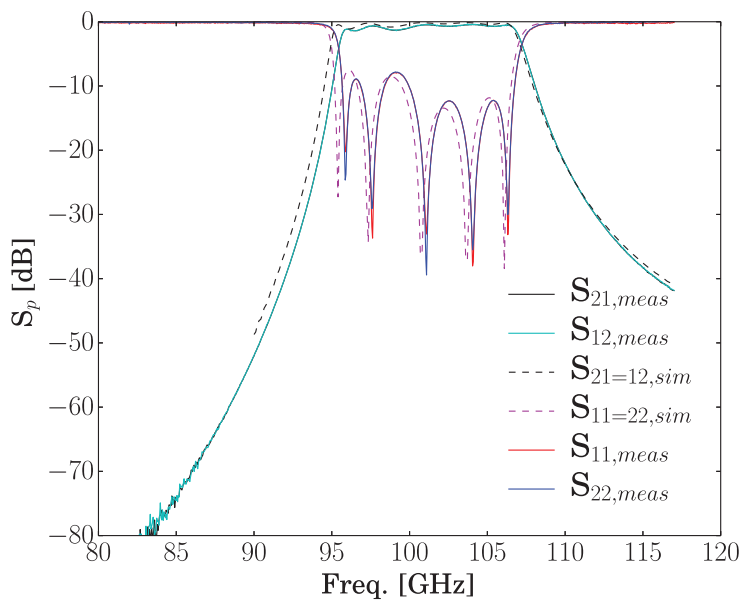

FIG. 5. Simulated and measured transmission characteristics $\left(S_{21}\right.$ and $\left.S_{12}\right)$, input matching $\left(S_{11}\right)$, and output matching $\left(S_{22}\right)$ of the five-pole bandpass filter in the E-plane cut.

$3.4 \%$. The largest insertion loss in the passband is about 1.4 $\mathrm{dB}$ for frequencies around $96 \mathrm{GHz}$, and the lowest insertion loss in the passband is about $0.4 \mathrm{~dB}$ for frequencies around $104 \mathrm{GHz}$. The lower rejection (attenuation roll-off) is larger than $22 \mathrm{~dB}$ for all frequencies lower than $94 \mathrm{GHz}$, while the upper rejection is larger than $20 \mathrm{~dB}$ in the range $110-117$ $\mathrm{GHz}$. The measured matchings in the filter passband at the input port 1 and the output port 2, corresponding to $S_{11}$ and $S_{22}$ in Fig. 5, respectively, are $9 \mathrm{~dB}$ or higher showing good agreement with the simulations. Furthermore, we notice good agreement between the measurements of $S_{11}$ and $S_{22}$ which indicates that the symmetric filter halves are fabricated accurately. The shape of the attenuation roll-off matches the simulation very well which implies that the Q-factors determined by the simulator are in agreement with the physical conductor loss in brass.

Measured and simulated transmission characteristics in the out-of-band frequency range $140-220 \mathrm{GHz}$ (G-band) are shown in Fig. 7. The input and output matchings $\left(S_{11}\right.$ and $S_{22}$ ) are of less importance since the secondary passband is not used for signal transmission, but we are rather interested in how much attenuation we can expect for radiation

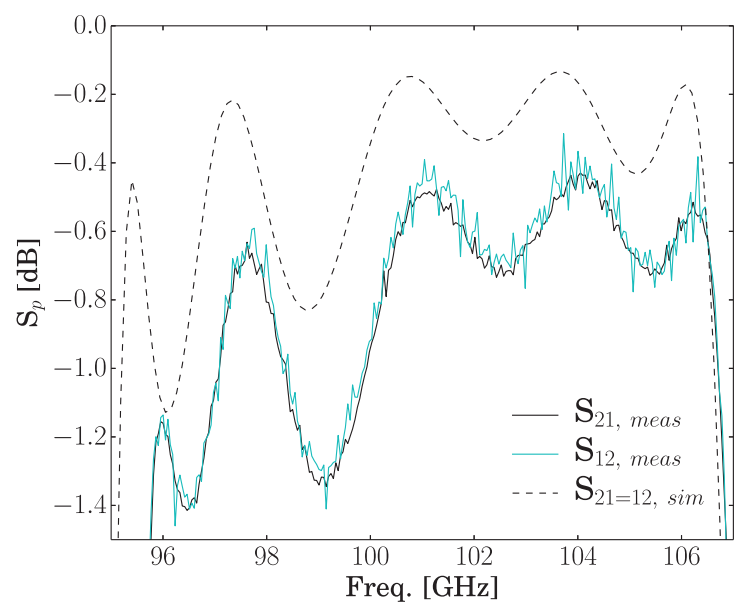

FIG. 6. Zoom in view of the simulated and measured transmission characteristics in the passband presented in Fig. 5. 


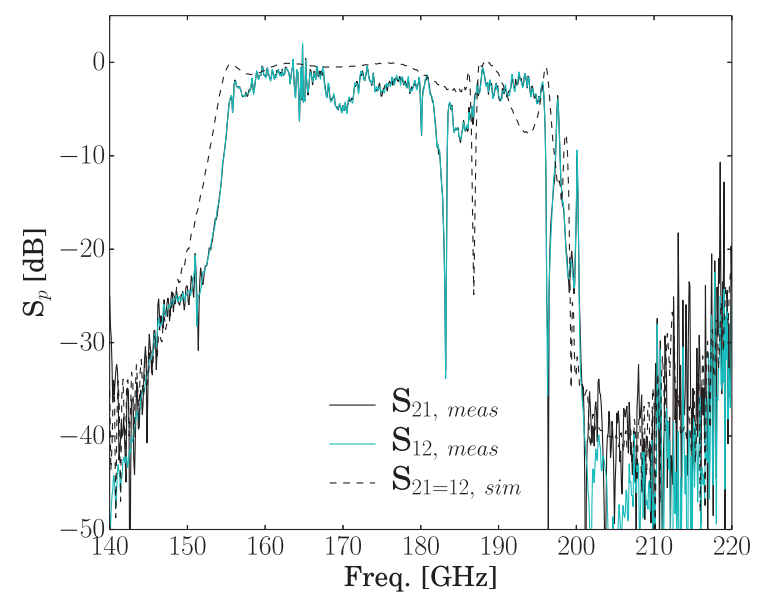

FIG. 7. Simulated and measured out-of-band transmission characteristics of the five-pole bandpass filter in E-plane cut topology.

coming from the ECRH gyrotrons operating at $140 \mathrm{GHz}$. The measurements in the G-band are accomplished using the programmable network analyzer (PNA-X) N5242A-400 with four ports attached to a pair of $\mathrm{OML}^{28}$ frequency extenders with WR-05 waveguide flanges. Each OML extender has one local oscillator (LO) port and one radio frequency (RF) port that are connected to the PNA-X ports. The measurements in Fig. 7 show appearance of a secondary passband with relatively low insertion loss in the range from 155 to $195 \mathrm{GHz}$ in accordance with the simulations. Eigenmode analysis shows that the first higher order mode of the smallest sections (no. 1 and no. 5) is approximately at $155 \mathrm{GHz}$, and that of the largest section (no. 3) is at approximately $195 \mathrm{GHz}$. We find that this filter attenuates unwanted signals in the range from 115 to $142 \mathrm{GHz}$ with a rejection larger than $40 \mathrm{~dB}$. By increasing the number of resonator sections to seven (seven-pole filter), it is possible to get steeper attenuation roll-off compared with a five-pole filter. However, the upper rejection bandwidth with minimum $40 \mathrm{~dB}$ attenuation would then shrink to the range $115-138 \mathrm{GHz}$ and thereby the $140 \mathrm{GHz}$ gyrotron radiation would be inadequately rejected.

\section{E-PLANE AND H-PLANE BANDPASS FILTERS - COMPARISON}

In our previous work, presented in Ref. 24, a similar bandpass filter was constructed using five resonator sections (poles) with a passband range from 100 to $110 \mathrm{GHz}$. The filter was divided into two halves using the H-plane cut, i.e., a cut at the position $b / 2$ where $b$ is the short side of the waveguide (see Fig. 8). A comparison of measured S-parameters

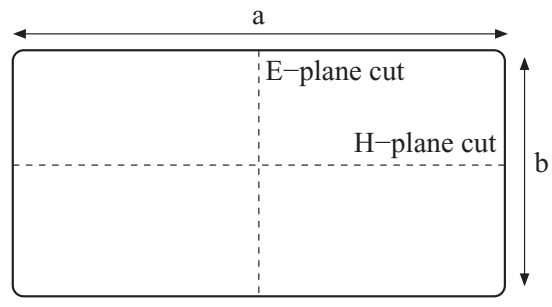

FIG. 8. General topology of E-plane and H-plane cuts for a rectangular waveguide following the dimension standard $a=2 \cdot b$.

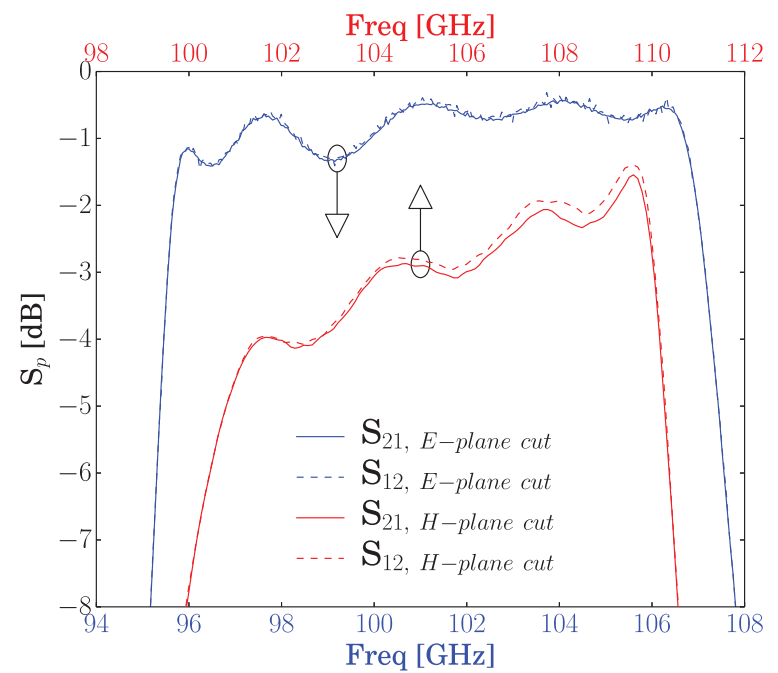

FIG. 9. Comparison between measured filter transmission characteristics $S_{21}$ and $S_{12}$ using E-plane cut presented in this paper and H-plane cut presented in Ref. 24.

of the H-plane filter and the E-plane filter are presented in Figs. 9 and 10. We designed the H-plane filter to have a passband $4 \mathrm{GHz}$ upshifted from our present E-plane filter. In Figs. 9 and 10, we therefore shift the $\mathrm{x}$-axis of the E-plane filter by $4 \mathrm{GHz}$ with respect to the $\mathrm{x}$-axis of the $\mathrm{H}$-plane filter, so that the S-parameters are easier to compare. Fig. 9 shows that the H-plane filter has, compared with the E-plane filter, a clear slope in the passband region with insertion loss around $4 \mathrm{~dB}$ at the low frequency end $(\approx 100 \mathrm{GHz})$ and around $2 \mathrm{~dB}$ at the high frequency end $(\approx 110 \mathrm{GHz})$. The E-plane filter has less than $1.4 \mathrm{~dB}$ insertion loss across its entire passband. The E-plane filter also has a significantly wider passband of about $10.37 \mathrm{GHz}$ compared with that of the H-plane filter of about $9 \mathrm{GHz}$. One possible explanation for the high insertion loss in the passband of the H-plane filter is that the H-plane cut introduces a discontinuity perpendicular to the surface current flow of the fundamental $\mathrm{TE}_{10}$ mode. Thereby the surface

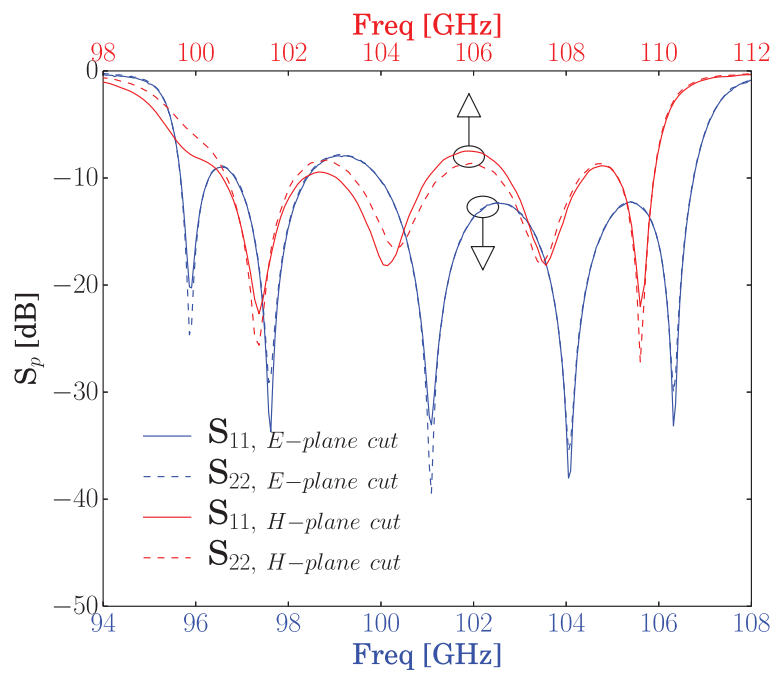

FIG. 10. Comparison between measured filter input matching and output matching $S_{11}$ and $S_{22}$, respectively, using E-plane cut presented in this paper and H-plane cut presented in Ref. 24. 


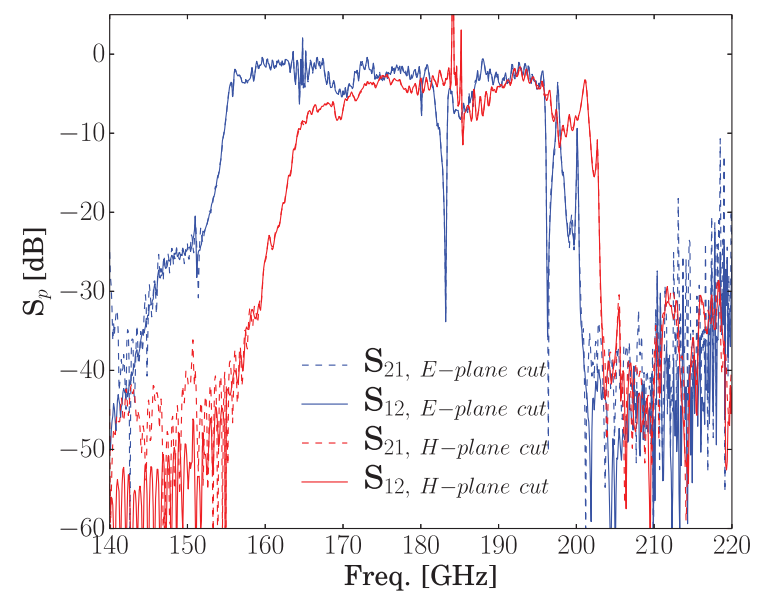

FIG. 11. Comparison between measured transmission characteristics in the out-of-band region using the E-plane cut presented in the paper and the $\mathrm{H}$ plane cut presented in Ref. 24.

currents are strongly affected by the H-plane discontinuity. This does not happen for the E-plane cut, since the surface current flow of the fundamental $\mathrm{TE}_{10}$ mode is parallel with the E-plane. The surface currents are therefore only marginally affected by the E-plane discontinuity. The discontinuities in either case were not taken into account in the simulations. In Fig. 10, we show matchings at the input port 1 and the output port 2 for both the E-plane and the H-plane filters. For the H-plane filter, the first resonance at low frequencies does not create clear minima in $S_{11}$ or $S_{22}$, whereas that of the E-plane filter creates clear minima. Only four resonances appear clearly in the case of H-plane filter, whereas the expected five resonances in the passband range of the E-plane filter clearly appear.

The S-parameters for the out-of-band region measured from 140 to $220 \mathrm{GHz}$ are presented in Fig. 11 for both filters. The secondary passband for the E-plane filter appears in the range from approximately 155 to $195 \mathrm{GHz}$ and for the $\mathrm{H}$ plane filter from approximately 163 to $203 \mathrm{GHz}$. For both filters the shape of the S-parameters $S_{21}$ and $S_{12}$ are very similar. The secondary passband of the H-plane filter is upshifted by approximately $10 \mathrm{GHz}$ compared with the E-plane filter. Furthermore, the H-plane filter insertion loss is somewhat higher at the lower frequency end of the secondary passband compared with the remaining part of the secondary passband. The insertion loss around $140 \mathrm{GHz}$ is larger than $40 \mathrm{~dB}$ for both filter topologies as observed in the simulations.

\section{CONCLUSIONS}

We have constructed a five-pole bandpass filter with a passband from 96 to $106 \mathrm{GHz}$. The filter is cut in two halves using the E-plane cut. Since the filter passband determined by initial simulations (topology based on the direct coupling theory) was narrower than expected, we scaled the section lengths $l_{k}$ and iris openings $d_{k}$ with factors $\Delta_{l_{k}}=0.98$ and $\Delta_{d_{k}}=0.993$, respectively. The scaled geometry provided $\mathrm{S}$-parameters that were relatively close to the ideal values derived from Tchebyscheff's synthesis. Further improvements of the filter response were possible by optimizing section lengths $l_{k}$ and iris openings $d_{k}$ individually or combined. It turned out that it is sufficient to optimize the first (and the last) iris opening and the first (and the last) section length after scaling all sections and all iris openings.

The measured insertion loss of the E-plane filter is lower than $1.4 \mathrm{~dB}$ in the passband. S-parameter measurements of the filter agree very well with simulations with a discrepancy no larger than $0.4 \mathrm{~dB}$ in the passband. The measured passband width is approximately $3.4 \%$ narrower than in the simulation. The filter shows very good out-of-band rejection properties up to $142 \mathrm{GHz}$. Finally, we compare measured S-parameters of our E-plane filter with those of a very similar H-plane filter. We find that the E-plane filter has superior transmission and reflection characteristics compared with the H-plane filter.

\section{ACKNOWLEDGMENTS}

The authors would like to thank Carl-Magnus Kihlman for fabrication of the filter.

${ }^{1}$ H. J. Hartfuss, T. Geist, and M. Hirsch, "Heterodyne methods in millimetre wave plasma diagnostics with applications to ECE, interferometry and reflectometry," Plasma Phys. Control. Fusion 39(11), 1693-1769 (1997).

${ }^{2}$ V. Furtula, M. Salewski, F. Leipold, P. K. Michelsen, S. B. Korsholm, F. Meo, D. Moseev, S. K. Nielsen, M. Stejner, and T. Johansen, "Design and performance of the collective Thomson scattering receiver at ASDEX Upgrade," Rev. Sci. Instrum. 83(1), 013507 (2012).

${ }^{3}$ M. Salewski, F. Meo, M. Stejner, O. Asunta, H. Bindslev, V. Furtula, S. B. Korsholm, T. Kurki-Suonio, F. Leipold, F. Leuterer, P. K. Michelsen, D. Moseev, S. K. Nielsen, J. Stober, G. Tardini, D. Wagner, P. Woskov, and the ASDEX Upgrade team, "Comparison of fast ion collective Thomson scattering measurements at ASDEX Upgrade with numerical simulations," Nucl. Fusion 50(3), 035012 (2010).

${ }^{4}$ M. Salewski, S. K. Nielsen, H. Bindslev, V. Furtula, N. N. Gorelenkov, S. B. Korsholm, F. Leipold, F. Meo, P. K. Michelsen, D. Moseev, and M. Stejner, "On velocity space interrogation regions of fast-ion collective Thomson scattering at ITER,” Nucl. Fusion 51(8), 083014 (2011).

${ }^{5}$ M. Salewski, B. Geiger, S. K. Nielsen, H. Bindslev, M. García-Muñoz, W. W. Heidbrink, S. B. Korsholm, F. Leipold, F. Meo, P. K. Michelsen, D. Moseev, G. Stejner, M. Tardini, and the ASDEX Upgrade team, "Tomography of fast-ion velocity-space distributions from synthetic CTS and FIDA measurements," Nucl. Fusion 52(10), 103008 (2012).

${ }^{6}$ F. Meo, H. Bindslev, S. B. Korsholm, V. Furtula, F. Leuterer, F. Leipold, P. K. Michelsen, S. K. Nielsen, M. Salewski, J. Stober, D. Wagner, and P. Woskov, "Commissioning activities and first results from the collective Thomson scattering diagnostic on ASDEX Upgrade," Rev. Sci. Instrum. 79, 10E501 (2008).

${ }^{7}$ W. A. Bongers et al., "Commissioning of inline ECE system within waveguide based ECRH transmission systems on ASDEX Upgrade," EPJ Web Conf. 32, 03006 (2012).

${ }^{8}$ M. Salewski, F. Meo, H. Bindslev, V. Furtula, S. B. Korsholm, B. Lauritzen, F. Leipold, P. K. Michelsen, S. K. Nielsen, and E. Nonbøl, "Investigation of first mirror heating for the CTS diagnostic in ITER," Rev. Sci. Instrum. 79, 10E729 (2008).

${ }^{9}$ M. Salewski, O. Asunta, L.-G. Eriksson, H. Bindslev, V. Hynönen, S. B. Korsholm, T. Kurki-Suonio, F. Leipold, F. Meo, P. K. Michelsen, S. K. Nielsen, and J. Roenby, "Comparison of collective Thomson scattering signals due to fast ions in ITER scenarios with fusion and auxiliary heating," Plasma Phys. Control. Fusion 51(3), 035006 (2009).

${ }^{10}$ C. Straub, P. J. Espy, R. E. Hibbins, and D. A. Newnham, "Mesospheric CO above Troll station, Antarctica observed by a ground based microwave radiometer," Earth Syst. Sci. Data Discus. 5, 199-208 (2013).

${ }^{11}$ E. R. Brown, "Fundamentals of terrestrial millimeter-wave and THz remote sensing,” Int. J. Hi. Spe. Ele. Syst. 13, 995-1097 (2003).

${ }^{12}$ N. Marcuvitz, Waveguide Handbook (Peter Peregrinus Ltd., London, 1986).

${ }^{13}$ G. Matthaei, L. Young, and E. M. T. Jones, Microwave Filters, ImpedanceMatching Networks, and Coupling Structures (Artech House, Norwood, MA, 1980). 
${ }^{14}$ J. L. Altman, Microwave Circuits (D. Van Nostrand Company, Inc., 1964)

${ }^{15}$ C. G. Montgomery, R. H. Dicke, and E. M. Purcell, Principles of Microwave Circuits (The Maple Press Company, York, PA, 1948).

${ }^{16}$ X. H. Zhao, J. Bao, G. Shan, Y. Du, Y. Zheng, Y. Wen, and C. Shek, "D-band micromachined silicon rectangular waveguide filter," IEEE Microwave Wireless Compon. Lett. 22(5), 230-232 (2012).

${ }^{17}$ S. Song, C.-S. Yoo, and K.-S. Seo, "W-band bandpass filter using micromachined air-cavity resonator with current probes," IEEE Microwave Wireless Compon. Lett. 20(4), 205-207 (2010).

${ }^{18}$ C. A. Leal-sevillano, T. J. Reck, C. Jung-kubiak, G. Chattopadhyay, J. A. Ruiz-cruz, J. R. Montejo-garai, and J. M. Rebollar, "Silicon micromachined canonical E-plane and H-plane bandpass filters at the terahertz band," IEEE Microwave Wireless Compon. Lett. 23(6), 288-290 (2013).

${ }^{19}$ G. Prigent, E. Rius, F. Le pennec, S. Le maguer, C. Quendo, G. Six, and H. Happy, "Design of narrow-band DBR planar filters in Si-BCB technology for millimeter-wave applications," IEEE Trans. Microwave Theory Tech. 52(3), 1045-1051 (2004).

${ }^{20}$ C.-S. Yoo, J.-M. Maeng, N.-C. Cheon, S. Song, and K.-S. Seo, "W-band compact bandpass filters on thin-film substrate," Microwave Opt. Tech. Lett. 52(3), 750-753 (2010).
${ }^{21}$ F. Aryanfar and K. Sarabandi, "Compact millimeter-wave filters using distributed capacitively loaded CPW resonators," IEEE Trans. Microwave Theory Tech. 54(3), 1161-1165 (2006).

${ }^{22}$ H. N. Van, T. H. Anh, J.-H. Kim, Y.-H. Baek, S.-J. Lee, M. Han, Y.-S. Chae, S.-D. Kim, J.-K. Rhee, J.-H. Jung, and Y.-W. Park, "Low-loss Wband CPW bandpass filter using annular CPW branchline coupler with open load stubs," Microwave Opt. Tech. Lett. 53(10), 2400-2403 (2011).

${ }^{23}$ M. Zhao, Y. Fan, Z. Yang, Y. Zhang, and J. Zhan, "A W-band low loss E-plane type waveguide bandpass filter," IEEE 2007 International Symposium on Microwave, Antenna, Propagation, and EMC Technologies For Wireless Communications (IEEE, 2007), pp. 355-357.

${ }^{24}$ V. Furtula, H. Zirath, and M. Salewski, "Waveguide bandpass filters for millimeter-wave radiometers," Int. J. Infr. Millimeter Waves 34(12), 824836 (2013).

${ }^{25}$ P. A. Rizzi, Microwave Engineering - Passive Circuits (Prentice-Hall, Englewood Cliffs, NJ, 1988).

${ }^{26}$ Computer Simulation Technology (CST), Microwave studio, 2012.

${ }^{27}$ A. Agarwal and L. T. Biegler, "A trust-region framework for constrained optimization using reduced order modeling," Optimization and Eng. 14(1), 3-35 (2013).

${ }^{28}$ Oleson Microwave Laboratories (OML) Inc., V05VNA-T/R, 2008. 